\title{
CLINICAL MANIFESTATIONS, VITAL SIGNS, AND BOWEL VIABILITY IN PEDIATRIC INTUSSUSCEPTION
}

\section{Erwin Siregar}

\section{Department Of Surgery, Faculty Of Medicine Universitas Sumatera Utara/h.} Adam Malik General Hospital, Medan

ABSTRACT INTRODUCTION: Intussusception is a condition in which part of the intestine slides into an adjacent part of the intestine. Intussusception is an important cause of an acute abdomen and the second most common cause of bowel obstruction in children. The classic triad of intussusception, including vomiting, abdominal colic pain and bloody stool. However, the triad has only been reported in $<50 \%$ cases. This study is aimed to evaluate the clinical manifestation, vital signs, and bowel viability in pediatric intussusception.

METHODS: This is an observational retrospective study with total sampling.

RESULTS: Based on clinical characteristics, there were $44.44 \%$ subjects who had manifestations for 2-3 days. Ileocolic was the most common location (77.78\%). Majority of the subjects did not have the classic triad (66.67\%), had red currant jelly stool $(62.96 \%)$, did not have abdominal mass $(59.26 \%)$, complained of abdominal pain $(70.37 \%)$, did not have abdominal distention (74.07\%), did not vomit (55.5\%), was lethargic $(59.26 \%)$, and had viable bowel $(62.96 \%)$.

CONCLUSION: This study found that the most common manifestations of intussusception in children were abdominal pain, red currant jelly stool, and lethargy, with viable bowel and located at ileocolic.

\section{KEYWORDS : Intussusception, Characteristics, Triad, Viability.}

\section{INTRODUCTION}

Intussusception is the invagination of one part of the intestine into another. It involves three cylinders of intestinal wall, in which the inner and the middle cylinders are the invaginated bowel, the outer cylinder is the recipient of the invaginated bowel ${ }^{7}$.

Intussusception is one of the most common abdominal emergencies for children ${ }^{8}$. It is the second most common cause of acute abdomen and bowel obstruction in children ${ }^{2,18}$. The worldwide incidence was estimated around $1 / 10.000$ children and $1 / 1.000$ emergency department $\operatorname{cases}^{8,13}$.

The diagnosis of intussusception is challenging. Symptoms might not be specific and wide-ranging. Triad of classic symptoms were reported: vomiting, colicky abdominal pain, and bloody stool. However, the triad was reported only occurred in $<50 \%$ case $^{15}$.

This study was aimed to evaluate the characteristics of clinical manifestations, vital signs, and bowel viability in pediatric intussusception.

\section{METHODS}

This study took place from December 2018 until May 2019 at Adam Malik General Hospital. This is an observational study with retrospective design. Samples was taken using total sampling technique. The population was all patients with an intussusception diagnosis in the hospital. Patients who were enrolled in 2016 to 2018 , aged < 18 year old, and undergone surgery, were included in the study. Univariate analysis was performed.

\section{RESULTS}

A total of 27 patients were included in this study. Distribution of subject characteristics was shown in Table 1. Eighteen $(66.67 \%)$ out of 27 subjects were male. Majority of subjects $(40.73 \%)$ aged $4-6$ months. Table 2 showed distributions of vital signs, with predominant normal vital signs.

Tabel 1. Distribution of Subjects' Characteristics

\begin{tabular}{|c|c|c|}
\hline Variable & Frequency & Percentage (\%) \\
\hline Male & 18 & 66.67 \\
\hline Female & 9 & 33.33 \\
\hline \multicolumn{3}{|c|}{ Age (months) } \\
\hline
\end{tabular}

\begin{tabular}{|c|c|c|}
\hline $0-3$ & 4 & 14.81 \\
\hline $4-6$ & 11 & 40.73 \\
\hline $7-12$ & 8 & 29.63 \\
\hline $13-24$ & 2 & 7.41 \\
\hline$>24$ & 2 & 7.41 \\
\hline
\end{tabular}

Table 2. Distribution of Subjects' Vital Signs

\begin{tabular}{|c|c|c|}
\hline Variable & Frequency & Percentage (\%) \\
\hline \multicolumn{3}{|c|}{ Blood pressure } \\
\hline Normal & 20 & 74.07 \\
\hline Elevated & 7 & 25.93 \\
\hline \multicolumn{3}{|l|}{ Heart rate } \\
\hline Normal & 21 & 77.78 \\
\hline Elevated & 6 & 22.22 \\
\hline \multicolumn{3}{|c|}{ Respiratory rate } \\
\hline Normal & 19 & 70.37 \\
\hline Elevated & 8 & 29.63 \\
\hline \multicolumn{3}{|l|}{ Temperature } \\
\hline Normal & 21 & 77.78 \\
\hline Hyperthermia & 5 & 18.52 \\
\hline Hyperpyrexia & 1 & 3.70 \\
\hline
\end{tabular}

Clinical characteristics were shown in Table 3. Only 5 (18.52\%) subjects who had symptoms for one day, and almost half $(44.44 \%)$ with duration of symptoms of 2-3 days. Based on the location, ileocolic was the most common with a total of 21 $(77.78 \%)$ subjects. Intussusception involving two different spots were found only in one $(3.70 \%)$ subject; ileocolic and colocolic.

Table 3. Clinical Characteristics of Subjects

\begin{tabular}{|c|c|c|}
\hline \multicolumn{3}{|c|}{ Daration (day) } \\
\hline 1 & 5 & Percentage (\%) \\
\hline $2-3$ & 12 & 18.52 \\
\hline$\geq 4$ & 10 & 44.44 \\
\hline \multicolumn{3}{|c|}{ Location } \\
\hline Ileocolic & 21 & 37.04 \\
\hline Ileocaecal & 2 & 77.78 \\
\hline Ileoileal & 1 & 3.41 \\
\hline Ileocolocolic & 1 & 3.70 \\
\hline Colocolic & 1 & 3.70 \\
\hline Ileocolic + & 1 & 3.70 \\
colocolic & Triad \\
\hline \multicolumn{3}{|c|}{} \\
\hline
\end{tabular}




\begin{tabular}{|c|c|c|}
\hline Yes & 9 & 33.33 \\
\hline No & 18 & 66.67 \\
\hline \multicolumn{3}{|c|}{ Red currant jelly stool } \\
\hline Yes & 17 & 62.96 \\
\hline No & 10 & 37.04 \\
\hline \multicolumn{3}{|c|}{ Mass on palpation } \\
\hline Yes & 11 & 40.74 \\
\hline No & 16 & 59.26 \\
\hline \multicolumn{3}{|c|}{ Abdominal colic } \\
\hline Yes & 19 & 70.37 \\
\hline No & 8 & 29.63 \\
\hline \multicolumn{3}{|c|}{ Abdominal distention } \\
\hline Yes & 7 & 25.93 \\
\hline No & 20 & 74.07 \\
\hline Yes & 12 & 44.44 \\
\hline No & 15 & 55.56 \\
\hline \multicolumn{3}{|c|}{ Lethargy } \\
\hline Yes & 16 & 59.26 \\
\hline No & 11 & 40.74 \\
\hline Viable & 17 & 62.96 \\
\hline Not viable & 10 & 37.04 \\
\hline Bowel viability \\
\hline $33 \%)$ \\
\hline
\end{tabular}

symptom duration. In this study, as many as $44.44 \%$ subjects had 2-3 days of symptoms, and $37.04 \%$ had $\geq 4$ days of symptoms. Previous literature stated that ischaemic necrosis begins at 72 hours in most cases ${ }^{7}$.

Majority of the cases were located at ileocolic. This is similar with the study by (2013) (68\%), Rengarajan et al (2017) (72/74), and Caruso et al (2017) (93\%). Only 3.7\% subjects in this study had intussusception at two different locations. Previous studies had reported that intussusception at two or more locations were indeed rarely found in children, and there were only few reports ${ }^{16,20}$.

Duration of symptoms till subjects sought medical advice was $2-3$ days in $44.44 \%$ subjects and $\geq 4$ days in $37.04 \%$ subjects. This was similar to previous findings, Singh \& Singh (2015) reported that only $13.6 \%$ subjects had duration of symptoms $24-48$ hours, $33.6 \%$ with duration of $48-72$ hours, and $52.72 \%$ with duration of $>72$ hours. The length of symptoms until patients seek medical advice might be related to patients age, as younger children might not be able to utter the symptoms.

Most of the subjects in this study were male. A Japanese guideline for pediatric intussusception, stated that the ratio of male-to-female was $2: 1^{12}$, and three other wide-scale epidemiologic studies reported male-to-female ratio $1.6: 1$ to $2.1: 1^{4,6,10}$. Though the numbers of ratio were different, those studies indicated that predominance of male patients in pediatric intussusception ${ }^{21}$. Nonetheless, the reason was not explainable.

The subjects were most commonly aged 4-6 months, followed by $7-12$ months. This was along with the study conducted by Ahmad et al (2016), which reported that $68 \%$ of pediatric intussusception patients aged 6-12 months. However, this result differed from the one by Muhsen et al (2014), where subject aged 6-11 months constituted almost half (40\%) of the subjects. A literature also stated that $75 \%$ intussusception cases occurred before 2 year old, and $90 \%$ occurred before 3 year old. It was still unknown the reason of tendency of occurrence between that range of age ${ }^{7}$.

This study had several limitations such as the study was conducted in one health centre only. Moreover, Adam Malik Public Hospital might have limited kind of cases, as it was a highest level of health care. The management was also limited, which there was no cases treated by open reduction. Several variables might also cause bias, such as the information of pain that might not be clearly known by history taking from the parents.

\section{REFERENCES}

1. Ahmad, M.M., Wani, M.D., Dar, H.M., Mir, I.N., Wani, H.A., Raja, A.N., 2016. An experience of ultrasound-guided hydrostatic reduction of intussusception at a tertiary care centre. S Afr J Surg, 54(1): 10-13.

2. Alhasani, A.A., 2016. Assessment of intraoperative manual reduction of Intussusception in children. Bas J Surg, 22: 69-76.

3. Bowker, B., Rascati, S., 2018. Intussusception. JAAPA, 31(1): 48-49.

4. Buettcher, M., Baer, G., Bonhoeffer, I. Schaad, U.B., Heininger, U., 2007. Three-year surveillance of intussusception in children in Switzerland. Pediatrics, 120: 473-80

5. Caruso, A.M., Pane, A., Scanu, A. et al, 2017. Intussusception in children: not only surgical treatment. J Pediatr Neonat Individual Med, 6(1): e060135.

6. Chang, H.G., Smith, P.F., Ackelsberg, J., Morse, D.L., Glass, R.I., 2001 Intussusception, rotavirus diarrhea, and rotavirus vaccine use among children in New York State. Pediatrics, 108: 54-60.

7. Columbani, P.M., Scholz, S. Intussusception. In: Coran AG, Caldamone A Adzick NS et al. Pediatric Surgery E-Book: Expert Consult - Online and Print, 7th ed. US: Elsevier Saunders; 2012. 1093-1110.

8. Dabadie, A., Petit, P. Acute Intestinal Intussusception. In: Avni FE, Petit P, eds Imaging Acute Abdomen in Children. US: Springer International Publishing; 2018. 167-177.

9. Fernandes, E.G., Leshem, E., Patel, M. et al, 2016. Hospital-based surveillance of intussusception among infants. J Pediatr (Rio J), 92(2): 181-187.

10. Fischer, T.K., Bihrmann, K., Perch, M. et al, 2004. Intussusception in early childhood: a cohort study of 1.7 million children. Pediatrics, 114: 782-5.

11. Gunawan, P.Y., 2018. Pediatric Ileocolic Intussusception Caused by 
Introducing Solid Food Before 6 Months Old: A Case Report. Pediatr Ther, 8(1): 343.

12. Ito, Y., Kusakawa, I., Murata, Y. et al, 2012. Japanese guidelines for the management of intussusception in children, 2011. Pediatrics International, 54, 948-958, e35-e42.

13. Jiang, J., Jiang, B., Parashar, U. et al, 2013. Childhood intussusception: $\alpha$ literature review. PLoS One, 8(7): e68482.

14. Johnson, B., Gargiullo, P., Murphy, T.V., Parashar, U.D., Patel, M.M., 2012 Factors Associated With Bowel Resection Among Infants With Intussusception in the United States. Pediatric Emergency Care, 28(6): 529-532.

15. Kapoor, T., McGee, R.G., Karpelowsky, J., Su, M., Webster, A.C., 2007. Surgical and non-surgical management for intussusception in children. Cochrane Database of Systematic Reviews, 2: CD006476.

16. Kızılyıldız, B.S., Beger, B., Sönmez, B., Karaman, K., 2016. Multiple Ileo-ileal Intussusceptions in a 3-Year-Old Child. Eur J Gen Med, 13(2): 152-154.

17. Kusmaheidi, S., Diposarosa, R., Nugraha, H.G., 2015. Pattern of Intussusceptions on Infants and Children in Dr. Hasan Sadikin General Hospital Bandung from 2009 to 201 l. AMJ, 2(3): 458-62.

18. Loukas, M., Pellerin, M., Kimball, Z., de la Garza-Jordan, J., Tubbs, R.S. Jordan, R., 2011. Intussusception: An Anatomical Perspective With Review of the Literature. Clinical Anatomy, 24: 552-561.

19. Padilla, B.E., Moses, W., 2017. Lower Gastrointestinal Bleeding \& Intussusception. Surg Clin N Am, 97: 173-18.

20. Shiu, J.R., Chao, H.C., Chen, C.C., Chi, C.Y., 2010. Rare Concurrent Ileoileal and Ileocolic Intussusceptions in a Child Presenting with Painless Hematochezia. Pediatr NeonatoL, 51 (6): 359-362.

21. Singh, I.K., Singh, L.C., 2015. A clinical study of intussusception in children. IOSR-JDMS, 14(12): 61-64 